\title{
A Measure of Child Exposure to Household Material Deprivation: Empirical Evidence from the Portuguese Eu-Silc
}

\author{
Maria Eugénia Ferrão ${ }^{1,2}$ (D) $\cdot$ Amélia Bastos $^{2,3} \cdot$ Maria Teresa G. Alves $^{4}$ (D
}

Accepted: 30 June 2020 / Published online: 4 August 2020

(C) The Author(s) 2020

\begin{abstract}
Although monitoring and evaluating child poverty has been recognized as important, there is little statistical information focused on children. Because the annual EUStatistics on Income and Living Conditions (EU-SILC) survey does not include child-specific information on an annual basis, this study proposes a measure of child exposure to household material deprivation based on this dataset. The study considers four domains of deprivation that have a direct impact on child development: housing conditions, household financial capacity, household durable goods, and environmental living conditions. Although developing a child-centered measurement of child deprivation is important, the EU-SILC considers the household as the unit of measurement. Therefore, our proposal is household-based, allowing annual monitoring of children's exposure to deprivation - an important insight for social policy purposes to tackle the problem of child poverty. Using the 2017 Portuguese sample, we applied graded response models to assess the psychometric properties of the EU-SILC items and fit separate indexes per domain and the composite index. Item selection was based on their characteristic curves and information functions. The results allow for the selection of more informative items for every domain to obtain the composite index. In general, the empirical analysis confirmed the theoretical approach for item selection. The methodology may be directly applied to the full EU dataset or to each country individually.
\end{abstract}

Keywords Child deprivation · Child development · Graded response model · Household poverty

JEL Classification I32 · FOS Classification · 5.1, 5.2, 5.3 · MSC Classification · 62P20, $62 \mathrm{~J} 12$.

Maria Eugénia Ferrão

meferrao@ubi.pt

Extended author information available on the last page of the article 


\section{Introduction}

Although monitoring and evaluating child poverty has been recognized as important, there is little statistical information focused on children. The national data available for use are primarily collected at the household level, allowing only an indirect evaluation of children's wellbeing through the lens and living conditions of the adults with which they live. The methodological options beyond measurements employed to analyze child poverty condition our understanding of the problem, and, consequently, the effectiveness of the social policies pursued to alleviate it.

The income-based approach to child poverty was the first methodological framework used to identify poor children. Because of the availability and easy access to data about household income, this procedure is still commonly used. However, this framework may cause serious bias in the analysis of the problem. In fact, poverty experienced by children differs from that experienced by adults not only in terms of the experience itself (Boyden et al. 2012) but also regarding its long-term consequences for children (Qi and Wu 2019). Moreover, children's basic achievements in education, health, housing, and social participation are also determined by the public services offered. These provisions may overcome household financial difficulties. Finally, the incomebased approach is based on the hypothesis that resources in a household are equally shared, which is a non-consensual conjecture (Main and Bradshaw 2016).

Empirical evidence has demonstrated the importance of household income for children's wellbeing, as it provides the basic living conditions for development (Cooper and Stewart 2013). Studies developed in the EU (Ajzenstadt and Gal 2010; European Commission 2008; Tarki 2010) analyze the effect of household income on children's wellbeing and their economic and social success as adults. Although these studies point out the importance of family income for children's wellbeing, they also note that income is not the sole determinant of children's wellbeing, which calls for use of a multidimensional approach to child poverty. Moreover, empirical evidence shows that many non-income poor suffer from multiple deprivations (Minujin 2012; Nolan and Whelan 2010).

The use of multidimensional measurements of child poverty is fairly well accepted (Author 2016; Ben-Arieh 2000; Guio et al. 2018; Saunders and Brown 2019). Townsend's (1979) pioneering method through the concept of deprivation has established the basis of multidimensional approaches to poverty. In 2004, UNICEF (2004) introduced the first official multidimensional proposal for child poverty analysis. Gordon et al. (2003) developed an evaluation of child poverty in developing countries by defining seven deprivation dimensions. The Multidimensional Poverty Index, which reflects the multiple deprivations faced by children, was applied to child poverty by Alkire and Roche (2011). More recently, Guio et al. (2018) examined 17 indicators and proposed a multidimensional measure of child deprivation for child poverty analysis. In the view of Ben-Arieh (2000), however, these studies are mostly concentrated on the analysis of children's present conditions or child wellbeing rather than on their future-child well-becoming.

The multidimensional approach to child poverty underlies the concept of child wellbeing "as the realisation of children's rights and the fulfilment of the opportunity for every child to be all she or he can be in the light of a child's abilities, potential and skills. The degree to which this is achieved can be measured in terms of positive child 
outcomes, whereas negative outcomes and deprivation point to the neglect of children's rights" (Bradshaw et al. 2007, p. 135). The UN Convention on the Rights of the Child (CRC) provides a normative framework to construct a definition of child wellbeing. These methods aim at encompassing the different meanings of child wellbeing. In the same vein, Amartya Sen's Capability Approach considers wellbeing to be related to the capacity to take different opportunities in accordance with individual preferences.

Indicators related to child wellbeing are of growing interest and have awakened long debates and minimum consensus (Ben-Arieh 2008). Child-centered analyses have been attempted (Gordon et al. 2003; Guio et al. 2018) but the scarcity of data focused on the child as the statistical unit of analysis and observation has conditioned the operationalization of these approaches.

Most of the multidimensional methods developed to investigate child poverty rely on datasets that use the household as the unit of measurement and, therefore, do not capture individual deprivations. Even if child-specific indicators are used within these frameworks, identification at the household level does not allow disentanglement of intra-household inequalities (Brown et al. 2017). Intra-household poverty analyses have shown significant disparities in the management and sharing of resources among household members. Pahl (2005) found gender disparities within UK households, and Daly et al. (2012) suggest these disparities may also affect children, as women often give greater priority to children's allocation of resources than men (Grogan 2004). In addition, children's needs vary according to age, and the youngest children may be more protected from resource restrictions than older ones (Ridge 2011). Main and Bradshaw (2016) affirm that children in the same household may have different statuses in terms of poverty. Finally, children are not usually the respondents, which may bias the evaluation of child wellbeing. In fact, there is increasing agreement on the importance of incorporating children's views and perceptions in the identification and evaluation process (Main and Bradshaw 2016).

Analyses of the mismatch between household and individual multidimensional poverty indices focused on children are scarce (Pinilla-Roncancio et al. 2019). The study developed by Pinilla-Roncancio et al. (2019) shows that profiles based on individual or household measurements of children identified as poor differ. They also found there are children experiencing multiple deprivations who live in non-deprived households and non-deprived children at the individual level who live in deprived households. When resources are limited, adults commonly sacrifice their own needs in favor of their children (Middleton et al. 1997). Moreover, research indicates there are children living in poor households that are not directly exposed to poverty (Main and Bradshaw 2016). Adults often prioritize children's needs, although we find that not all adults go without. In this context, multidimensional frameworks at the individual and household levels are complementary. The empirical evidence (Pinilla-Roncancio et al. 2019; Saunders and Brown 2019) suggests use of a composite measure that includes information at both the household and child levels. This measure may offer important insights for policy design.

The purpose of this study is to provide indexes of child exposure to material deprivation. We explore the main dataset used by the EU to analyze income, social inclusion, and living conditions - the European Union Statistics on Income and Living Conditions (EU-SILC), harmonized at the EU level and conducted annually- to evaluate child poverty. The annual statistics provided by this dataset are not child- 
focused but include detailed information about income and household living conditions, which are important determinants of children's wellbeing. Therefore, we propose a measure of child exposure to material deprivation that uses the household as the unit of observation and measurement, rather than a child poverty index. The study aims to (1) identify deprivation items at the household level that have an important impact on children's wellbeing, (2) group these items into deprivation domains, and (3) construct a composite index of child exposure to household material deprivation.

This study uses the Portuguese sample to compare the item composition of every domain of deprivation by applying graded response models (GRM) to three datasets. The first consists of the EU-SILC Portuguese dataset, the second is the dataset of households that include children (approximately 30\%), and the third is the dataset of households without children. The comparison is based on the item characteristic curves and item information functions for each domain, and it provides information on the items that are more sensitive to the presence of children. Our research offers an in-depth analysis of the 2017 EU-SILC Portuguese dataset aimed at constructing a measurement proposal to evaluate and monitor children's exposure to household deprivation on an annual basis.

Although the methodological proposal included in this research is household-based, it aims to give information about children's living conditions and opportunities that are intrinsically related to children's wellbeing. Therefore, our approach strives to give important insights for social policy design and monitoring, based on a reliable dataset, on an annual basis.

After this introduction, section 2 describes the data used and statistical models applied, section 3 examines the results obtained, and section 4 closes the study by setting out the principal findings and discussing their implications.

\section{Methodology}

\subsection{Instruments and Data}

We used the 2017 Portuguese sample of the EU-SILC, a survey anchored in the European Statistical System. The EU-SILC instrument provides two types of data: (1) cross-sectional data pertaining to a given time or a certain time period with variables on income, poverty, social exclusion, and other living conditions and (2) longitudinal data pertaining to individual-level changes over time, observed periodically over four years. In this study, we use cross-sectional data. Social exclusion and housing condition information is collected mainly at the household level, whereas labor, education, and health information are obtained for individuals ages 16 and over. The core of the instrument - income at a detailed component level — is mainly collected at the individual level (EUROSTAT 2018). This dataset is expected to be representative of the entire population and is EU country-comparable on issues related to labor markets, income, living standards, and education, among others.

According to the EU-SILC, the household population in 2017 was 4,117,770, of which 1,448,187 (35\%) had one or more dependent children (see Table 1).

Table 2 summarizes the 16 living condition items included in the dataset that reflect the theoretical determinants of children's wellbeing and presents the respective 
Table 1 Number of dependent children per household

\begin{tabular}{llrrll}
\hline & & Count & $\%$ & Cumulative \% \\
\hline Number of dependent children per household & 0 & $2,669,583$ & 64.83 & 64.83 \\
& 1 & 715,776 & 17.38 & 82.21 \\
& 2 & 419,269 & 10.18 & 92.40 \\
& $3+$ & 63,074 & 1.53 & 93.93 \\
& Other with children & 250,068 & 6.07 & 100.00 \\
& Total & $4,117,770$ & 100.00 & - \\
\hline
\end{tabular}

Source: Own calculation based on EU-SILC data with expansion weights DB090 (2020)

descriptive statistics. These items are also considered in other empirical studies (Bradshaw et al. 2007; Guio et al. 2018; Pinilla-Roncancio et al. 2019; Qi and Wu 2019). The items and their cut-offs are grouped into four domains of deprivation ${ }^{1}:(1)$ housing conditions, (2) household financial capacity, (3) comfort goods, and (4) housing environment. The selection of the deprivation domains and corresponding indicators follow the Alkire-Foster method (Alkire and Roche 2011). This method underlines the importance of empirical evidence, data accuracy, statistical properties, and data availability. We detail our choices as follows ${ }^{2}$ :

\section{(1) Housing conditions}

Housing is a critical issue for children (Clair 2019; Ridge 2011). This domain includes four items: overcrowded housing; leaking roof, damp walls, floors, foundation, or rot in window frames or floor; problems with the dwelling (e.g., too dark, not enough light); and bath or shower in the dwelling. The issues captured by the items considered the availability of space and the house structure, which not only directly impact children's health and comfort but also their social lives (Ridge 2011). The importance of housing also continues into adulthood. Marsh et al. (2000) note that health problems are more likely for adults living in non-deprived housing conditions if they lived in deprived housing conditions when they were children than for their peers who grew up in non-deprived housing.

(2) Household financial capacity

We consider five items in this domain: the ability to keep the home adequately warm; the existence of arrears on mortgage or rent payments; utility bills; purchase installments or other loan payments; and the ability to afford a meal with meat, chicken, or fish (or a vegetarian equivalent). The importance of household financial restrictions for children's wellbeing is well documented (Qi

\footnotetext{
${ }^{1}$ A child-centered analysis would necessarily be based on a different set of deprivation domains. Ben-Arieh (2000), for example, considers five domains of children's wellbeing: civil life skills, personal life skills, safety and physical status, children activities, and children economic status. Although these domains are of a different nature to those considered in our research, they also capture some of the issues raised by this approach.

${ }^{2}$ These choices are mostly supported by empirical studies, as well as by the statistical analysis developed in this study. Data availability was also taken into account, as this study is developed upon an in-depth analysis of the 2017 EU-SILC dataset. Discussing the theoretical models beyond the definition of deprivation domains and indicators fully is beyond the scope of this paper.
} 
Table 2 Descriptive statistics of items per deprivation domain

\begin{tabular}{|c|c|c|c|c|c|}
\hline \multirow[t]{2}{*}{ Domain } & \multirow[t]{2}{*}{ Item-Item label } & \multirow[t]{2}{*}{ Item category } & \multicolumn{3}{|c|}{$\begin{array}{l}\text { Children per } \\
\text { household }(\%)\end{array}$} \\
\hline & & & No & Yes & Both \\
\hline \multirow[t]{9}{*}{ Housing conditions } & \multirow[t]{2}{*}{ HH030_aux-Overcrowded house } & Yes & 1.08 & 12.11 & 4.32 \\
\hline & & No & 98.92 & 87.89 & 95.68 \\
\hline & \multirow[t]{2}{*}{ HH040-Drip/Damp dwelling } & Yes & 28.66 & 28.77 & 28.69 \\
\hline & & No & 71.34 & 71.23 & 71.31 \\
\hline & \multirow[t]{2}{*}{ HS160-Dimly lit dwelling } & Yes & 13.95 & 11.80 & 13.32 \\
\hline & & No & 86.05 & 88.20 & 86.68 \\
\hline & \multirow[t]{3}{*}{ HH081-Bath or shower in dwelling } & No & 2.06 & 0.68 & 1.65 \\
\hline & & Yes, shared & .49 & .17 & .40 \\
\hline & & Yes, for use in dwelling & 97.45 & 99.16 & 97.95 \\
\hline \multirow{17}{*}{$\begin{array}{l}\text { Household } \\
\text { financial capacity }\end{array}$} & \multirow[t]{3}{*}{ HH050-Home adequately warm } & No & 23.28 & 17.34 & 21.54 \\
\hline & & Yes & 76.71 & 82.66 & 78.46 \\
\hline & & NA/MV & .01 & 0.00 & .01 \\
\hline & \multirow{4}{*}{$\begin{array}{l}\text { HS011-Arrears on mortgage or } \\
\text { rent payments }\end{array}$} & Yes, two or more times & 1.29 & 3.91 & 2.06 \\
\hline & & Yes, once & .39 & .93 & .55 \\
\hline & & No & 32.08 & 62.11 & 40.90 \\
\hline & & NA/MV & 66.25 & 33.05 & 56.50 \\
\hline & \multirow[t]{4}{*}{ HS021-Arrears on utility bills } & Yes, two or more times & 3.31 & 7.04 & 4.41 \\
\hline & & Yes, once & .63 & 1.38 & .85 \\
\hline & & No & 94.25 & 88.99 & 92.71 \\
\hline & & NA/MV & 1.80 & 2.59 & 2.03 \\
\hline & \multirow{4}{*}{$\begin{array}{l}\text { HS031-Arrears on purchase } \\
\text { installments or other loan } \\
\text { payments }\end{array}$} & Yes, two or more times & 0.75 & 1.97 & 1.11 \\
\hline & & Yes, once & .18 & .62 & .31 \\
\hline & & No & 36.39 & 46.76 & 39.43 \\
\hline & & NA/MV & 62.69 & 50.65 & 59.15 \\
\hline & \multirow{2}{*}{$\begin{array}{l}\text { HS050-A meal with meat, } \\
\text { chicken, or fish every second day }\end{array}$} & No & 5.41 & 3.83 & 4.95 \\
\hline & & Yes & 94.59 & 96.17 & 95.05 \\
\hline \multirow[t]{13}{*}{ Comfort goods } & \multirow{3}{*}{$\begin{array}{l}\text { HS070-Communication facilities } \\
\text { (telephone/mobile phone) }\end{array}$} & No, for economic reason & 1.22 & .45 & .99 \\
\hline & & No, for another reason & 1.38 & .31 & 1.07 \\
\hline & & Yes & 97.40 & 99.24 & 97.94 \\
\hline & \multirow[t]{3}{*}{ HS080-Color TV } & No, for economic reason & .76 & .23 & .60 \\
\hline & & No, for another reason & .52 & .06 & .38 \\
\hline & & Yes & 98.72 & 99.72 & 99.02 \\
\hline & \multirow[t]{3}{*}{ HS090-Computer } & No, for economic reason & 8.58 & 6.42 & 7.95 \\
\hline & & No, for another reason & 39.56 & 2.53 & 28.68 \\
\hline & & Yes & 51.86 & 91.05 & 63.37 \\
\hline & \multirow[t]{4}{*}{ HS110-Car } & No, for economic reason & 9.02 & 6.73 & 8.35 \\
\hline & & No, for another reason & 21.86 & 2.87 & 16.28 \\
\hline & & Yes & 69.13 & 90.40 & 75.38 \\
\hline & & Yes & 21.10 & 22.16 & 21.41 \\
\hline
\end{tabular}


Table 2 (continued)

\begin{tabular}{|c|c|c|c|c|c|}
\hline \multirow[t]{2}{*}{ Domain } & \multirow[t]{2}{*}{ Item-Item label } & \multirow[t]{2}{*}{ Item category } & \multicolumn{3}{|c|}{$\begin{array}{l}\text { Children per } \\
\text { household }(\%)\end{array}$} \\
\hline & & & No & Yes & Both \\
\hline \multirow[t]{5}{*}{$\begin{array}{l}\text { Housing } \\
\quad \text { environment }\end{array}$} & $\begin{array}{l}\text { HS170-Noise from neighbors/from } \\
\text { the street }\end{array}$ & No & 78.90 & 77.84 & 78.59 \\
\hline & \multirow{2}{*}{$\begin{array}{l}\text { HS180-Pollution, crime, or other } \\
\text { environmental problems }\end{array}$} & Yes & 12.36 & 11.68 & 12.16 \\
\hline & & No & 87.64 & 88.32 & 87.84 \\
\hline & \multirow{2}{*}{$\begin{array}{l}\text { HS190-Crime, violence, or } \\
\text { vandalism in the area }\end{array}$} & Yes & 6.68 & 6.90 & 6.74 \\
\hline & & No & 93.32 & 93.10 & 93.26 \\
\hline
\end{tabular}

Legend: NA = Not applicable/MV = Missing value; Source: Own calculation (2019).

and $\mathrm{Wu} 2019)$. The family stress model points out the process in which economic stressors influence child wellbeing (Masarik and Conger 2017). For children, economic hardship may be responsible for serious material and social deprivations that go beyond adequate nutrition and health care, such as important symbolic social marks, including brands, extra-curricular activities, and leisure (Ridge 2011). Moreover, these restrictions are responsible for adult stress, which affects children through emotional contagion (Main and Bradshaw 2016). Household financial restrictions are also an important determinant of available resources for children's investment, especially regarding education, which conditions their life in adulthood (Ben-Arieh 2000). Finally, it should be mentioned that the family investment model also points out the importance of family economic resources on parental investments on children and, therefore, on their wellbeing and development (Kiernan and Huerta 2008).

(3) Comfort goods

In this domain, we include possession of goods such as communication facilities, a color television, and a car for private use. These are standard goods and, therefore, non-possession is associated with deprivation (Guio et al. 2018). Moreover, they support education and leisure activities. Once again, the family investment model considers that parents' social economic status is positively associated with child outcomes - higher parental status enables higher investment in materials and experiences that enrich and promote children's capacities and opportunities (Vasilyeva et al. 2018). The items included in this domain may be considered examples of such materials.

(4) Housing environment

In this domain, we include indicators that evaluate safety and pollution, important determinants of health and social life (Ridge 2011). The indicators considered include noise from neighbors or from the street; pollution, crime, or other environmental problems; and crime, violence, and vandalism in the area. Public space provisions also play an important role in disadvantaged neighborhoods. They may undermine housing conditions and financial restrictions (Sutton 2008). Adult hostility and crime are also problems identified by children as determinants of their wellbeing (Butler 2005). 


\subsection{Statistical Methods}

We applied the graded response model (GRM) (Samejima 1997), which allows the items to be on an ordinal scale, such as the polytomous item responses we have in the EU-SILC questionnaires. This is a unidimensional model for analyzing responses scored in two or more categories. When items have only two categories - that is, they are binary items - the GRM is equivalent to the two-parameter item response model. The GRM model is specified by Eq. (1),

$$
P_{i k}(\theta)=\frac{\exp \left[\sum_{j=1}^{k} \alpha_{i}\left(\theta-\beta_{i j}\right)\right]}{\sum_{c=1}^{m_{i}} \exp \left[\sum_{j=1}^{k} \alpha_{i}\left(\theta-\beta_{i j}\right)\right]} \quad\left(k=1, \ldots, m_{i}\right)
$$

where.

$i$ is the index related to the item $(i=1, . ., \mathrm{I}$; I is the total number of items);

$P_{i k}(\theta)$ is the probability that an individual with latent factor $\theta$ selected the $k^{\text {th }}$ category $\left(k=2,3, \ldots, m_{i}\right.$, and $m_{i}$ is the number of response categories for item $i$ );

$\alpha_{i}$ is the discrimination parameter for item $i$;

and $\beta_{i j}=b_{i}-d_{j}$, where $b_{i}$ is the difficulty/location parameter of item $i$ and $d_{j}$ is the parameter of the interception category, with $d_{1}=0$.

According to Eq. (1), the probability of selecting the $k^{\text {th }}$ category over the $m_{i}-1 s t$ category in a multicategory item is governed by the logistic dichotomous response model. Such probability is conditional on the answer in the $k-1$ category; that is, underlying the response to category $k$ is the response criteria satisfaction related to the previous category. According to the model assumption, the latent factor is unidimensional, that is, only one construct is being measured. In practice, however, this assumption does not strictly hold. Therefore, it is considered reasonable if there is a dominant factor in the data; in other words, item response models (IRM) will perform well as long as the latent factor being measured dominates the others (Zampetakis et al. 2015). This assumption was tested using the polychoric correlation matrix and principal component analysis (PCA) for all items together and for the subsets of items by domain.

To estimate the GRM parameters and fit the scales, we used the open-source R package mirt 1.3 (Chalmers 2012), which includes the marginal maximum likelihood approach using the Gauss-Hermite quadrature rule as the estimation procedure, and IRTPRO commercial software, which implements the maximum a posteriori estimation procedure (Cai et al. 2009). The item parameter estimation procedure is conditioned on the latent factor (theta) distribution as $\mathrm{N}(0,1)$.

\section{Results}

\subsection{Unidimensionality}

The descriptive analyses of all items together and the subsets of items per domain supported our assumption about the existence of more than one latent trait in the data matrix. The PCA with the 16 items resulted in four eigenvalues greater than 1 . The four 
respective factors explain $62 \%$ of the total variance. The correlation coefficients of the polychoric matrices are positive in every domain and the respective first eigenvalues are high enough to support the unidimensionality assumption (Hattie 1985; Reckase 1979). The first eigenvalues of housing environment and comfort goods account for more than $60 \%$ of the total variance. In the domain of housing conditions, the first eigenvalue accounts for $40 \%$ of the variance. In the domain of household financial capacity, there are two eigenvalues greater than 1, but the first, which accounts for $57 \%$ of the variance, is twice as high as the second. Based on the eigenvector analysis, we observe that the first eigenvector of each of the domains always presents absolute values close to 0.40 . Considering these results, we retained the four theoretically defined domains of deprivation.

\subsection{GRM Parameter Estimates}

The tables presented in Appendix A (supplementary file) include the GRM parameter estimates obtained for each domain. The estimates for $\alpha_{i}$ and $\beta_{i j}$ parameters are denoted by $a_{i}$ and $b_{i j}$, respectively. Such estimates allow graphical analysis either by the item characteristic curve (ICC) or item information curve (IIC). Figures 1 to 4 present ICC as left-axis and IIC as right-axis. The ICC. The ICC shows the probability that an individual/ household chooses a particular category of answer given his/her score in the latent trait, that is, the domain of deprivation. For each deprivation domain, the $\mathrm{x}$-axis, theta $(\theta)$, has the respective inverted scale with the standard deviation (SD) as the unit, meaning that the higher the $\theta$ is, the lower the deprivation level. The degree of severity of household deprivation, captured by the difficulty parameter, is observed for binary items at the point where the curves intersect. When ordinal variables are plotted, we observe the position of the curves of each category from left to right. The estimate of the discrimination parameter is the slope of the curve's tangent. The more upright the slope, the better the item's discriminating capacity and the higher its correlation with the deprivation domain.

The IIC plots can be used to evaluate how different items contribute to measurement accuracy at different levels of $\theta$. The higher the slope, the more information the item provides and the lower the measurement error. Thus, by analyzing an item's IICs, it is possible to identify those items that provide more information on the latent trait, reducing measurement errors and, consequently, determining items that can be discarded.

\subsubsection{Housing Conditions}

Figure 1 shows the combined ICC and IIC charts by dataset for the housing condition domain items. Item HH030_aux — overcrowded house - indicates distinct patterns across the three charts. In households with children (central chart), the probability line that represents that the household is not overcrowded (curve 0 ) crosses the probability line that represents that the household is overcrowded (curve 1) at a point between -3 and -2 SD of $\theta$. This point is far from $-3 \mathrm{SD}$ in households without children, and the respective curves 0 and 1 are flat. Also, the IIC curve (dotted line) suggests that the item adds information for households with children but does not add much information for households without children.

The analysis of the ICCs for HH040-leaking roof, damp walls/foundations/floor, rotting window frames or floor-shows similar patterns between households with and 


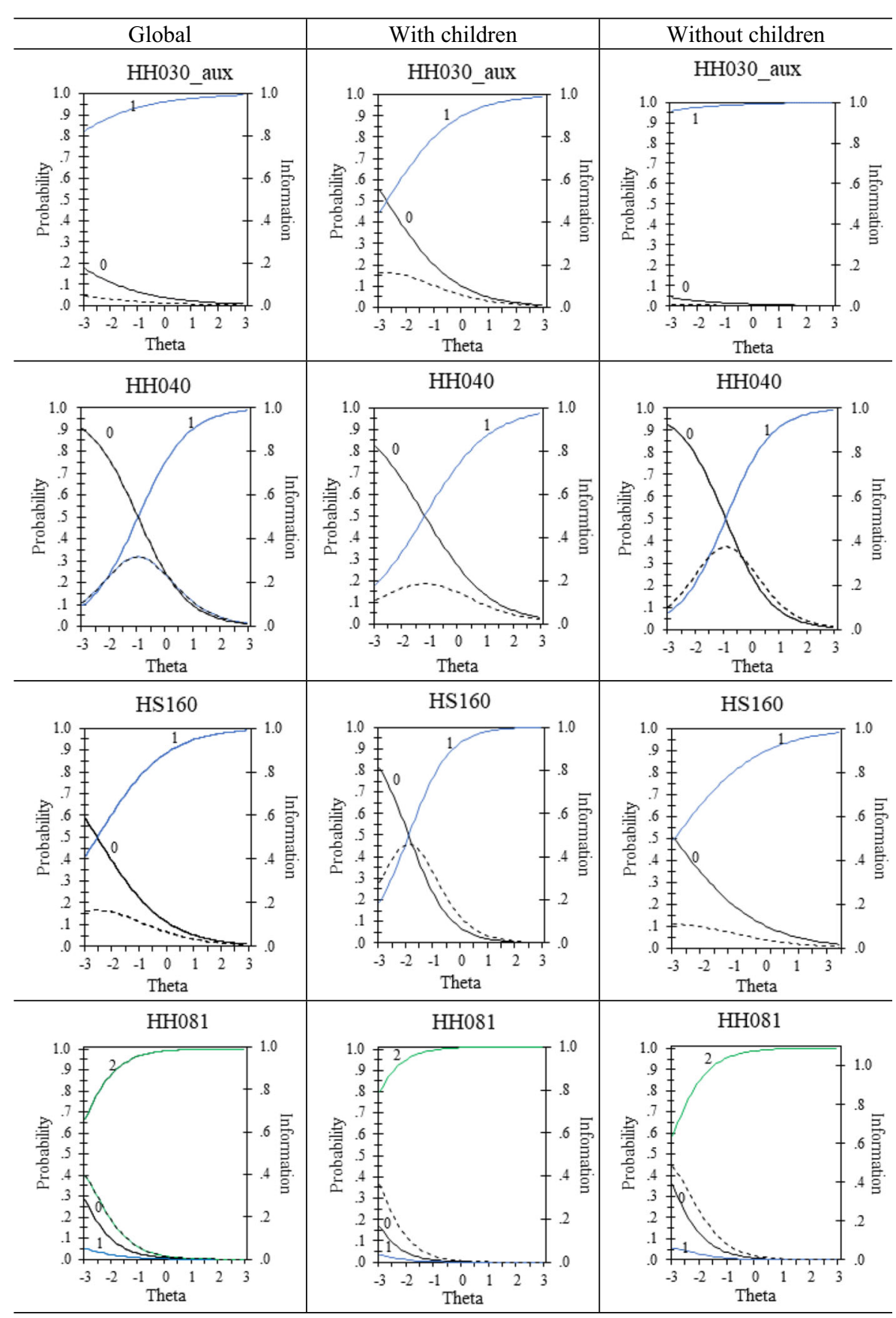

Source: Own calculation (2019).

Fig. 1 Item characteristic curves (ICC) and item information curves (IIC): housing condition items, Source: Own calculation (2019) 
without children. The IIC curve suggests the item is more informative about deprivation for households without children. This item provides information along most of the axis of theta and more accurately in the range between 0 and -2 SD.

Item HS160 - problems with the dwelling - captures the greater severity of lack of privacy in households with children; the intercept point is approximately $-2 \mathrm{SD}$. The IIC suggests the item is informative for households with children but provides very limited information for households without children. Thus, HS160 better discriminates the deprivation situation in households with children.

According to the descriptive statistics of item HH081-bath or shower in dwelling - presented in Table 2, greater than 97\% of households in the full dataset and the dataset of households without children have a bath or shower; this proportion is above $99 \%$ for households with children. This distribution explains that the ICC line for the first category, curve 1 , is less likely to be chosen, and its probability is not very distinguishable from the next response choice, curve 0 . Regarding the $\theta$ scale, these curves completely overlap, meaning that the categories could be aggregated without information loss. Thus, HH081 does not discriminate deprivation and provides scarce information for households with or without children.

\subsubsection{Household Financial Capacity}

Figure 2 shows the combined graphs by dataset, with the ICC curves (solid lines) and IIC curve (dotted line) for items related to the housing financial capacity domain. The ICC lines for item $\mathrm{HH} 050$ - ability to keep home adequately warm - have a similar shape across the three datasets. The lowest degree of severity provided by this item is observed in domiciles without children, as the lines intersect at -1 SD; in households with children, this point is to the left at -2 SD. The results suggest that children in households at that level of deprivation ( -2 SD) generally live in warmer houses than adults at the same level of deprivation who live in households without children. The item provides little information for estimating the latent trait in households with children, according to the IIC's shape, which is almost a flat line near the $\theta$ axis.

Item HS011-whether the household has been in arrears on mortgage or rent payments - has missing data due to nonapplicable households, but indicates the percentage is $33 \%$ in households with children (see Table 2). Despite this, the slope of the ICCs' tangent suggests this item discriminates the deprivation level well and also significantly captures the degree of severity of financial conditions. Each curve shows the selection probability of a category of the Item HS160 - problems with the dwelling - captures the smaller severity of dimly lit in households with children; the curves are slightly shifted to the right, which suggests less hardship for these families. The ordinal scale of this item is not justified, as the solid ICC lines referring to the "yes, once" and "yes, two or more times" options completely overlap. Therefore, the item could be dichotomized. According to the dotted lines (IIC), we notice that this item provides more information for households located between -1 and $-3 \mathrm{SD}$ on the scale of financial conditions, with a high level of precision in this range.

The next two items, HS021 and HS031 - arrears on utility bills and on purchase installments or other loan payments, respectively - are also ordinal variables, with the same categories as the former item and structural missing data. The ICCs and IICs present patterns similar to those of HS011. 


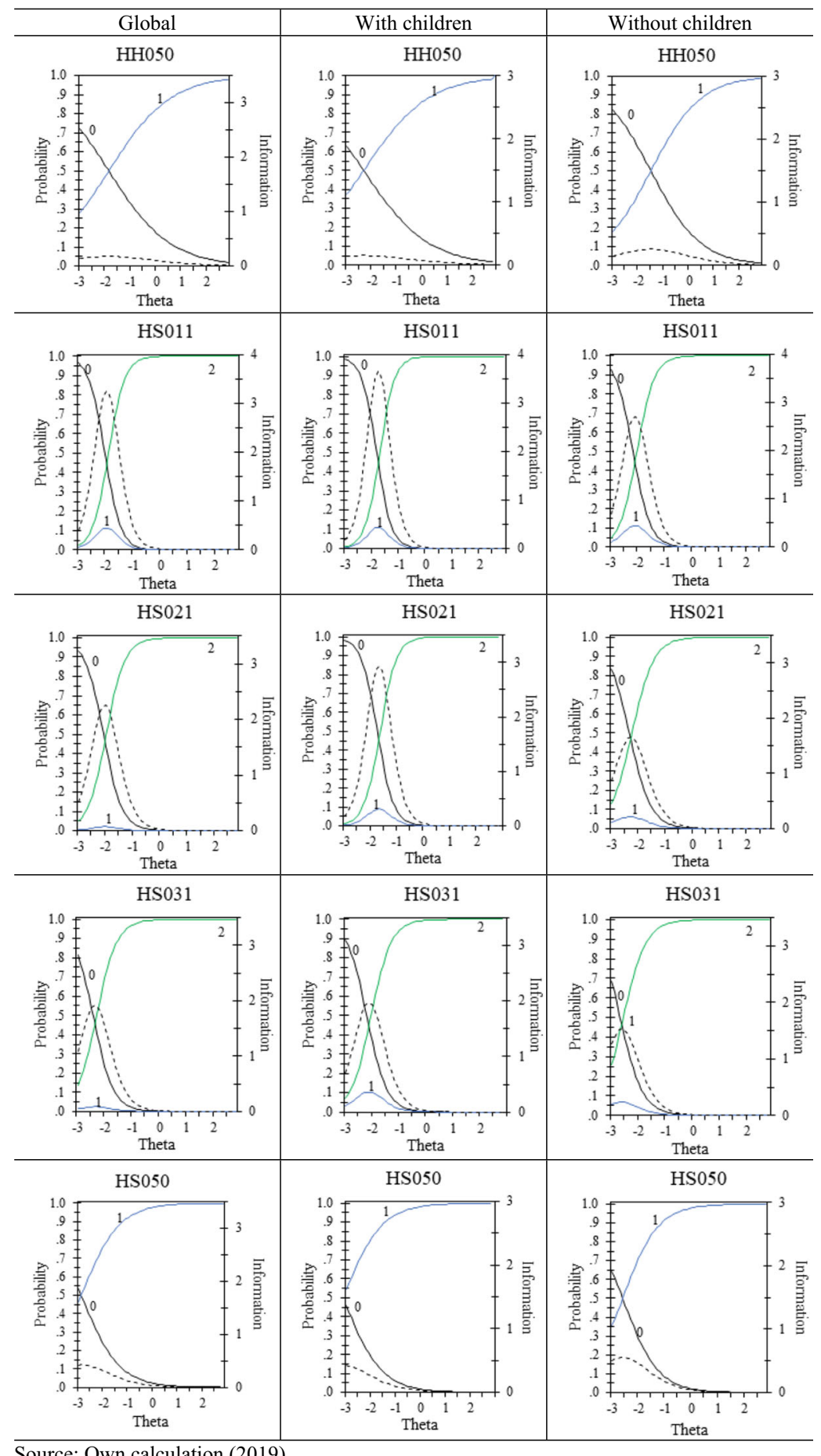

Source: Own calculation (2019)

Fig. 2 Item characteristic curves (ICC) and item information curves (IIC): housing financial capacity items, Source: Own calculation (2019) 
The ICCs for HS050 suggest that people living in households with children are likely to consume protein food. In fact, according to the descriptive analysis in Tables 2 , $95 \%$ in the full dataset and $96 \%$ in households with children regularly consume protein food. The IIC shows the amount of information provided by the item is very limited for households with children.

\subsubsection{Comfort Goods}

The items for the comfort goods domain were tested with three original response categories (see Table 2). Figure 3 shows the combined plotted ICC and IIC lines. The charts for HS070 and HS080-communication facilities and color TV, respectively - have similar patterns and seem to have limited relevance for discriminating deprivation in households with children.

Item HS090 - computer — presents an interesting ICC pattern, which differs between households with and without children. The well-inclined curves clearly distinguish households along the domain scale. Note that for the full dataset and the dataset for households without children, the curves spread widely over the x-axis, which is represented by the dotted IIC line. For households with children, the item presents a binary pattern (no or yes), as the first response category for the ICC completely overlaps the second, and the IIC reveals the item as making an important contribution to the information function.

The last item in this domain - HS110, possession of a car-presents ICCs similar to the previous ones, except that the levels of domain measurement precision are somewhat different according to the IIC dotted line. It seems rather more informative for households without children than for those with children.

\subsubsection{Housing Environment}

Figure 4 shows the combined ICC and IIC plot by dataset for the environment living condition items. All charts have similar shapes. Solid ICC lines show that all three items show a sufficient ability to measure levels of household environment deprivation. There is only a slight tendency for households with children to be in neighborhoods with less crime, violence, and vandalism (HS190). The IIC dotted line patterns are also similar across items and datasets. Overall, the evidence from this test is that conditions outside the home do not differ much between households with and without children.

\subsection{Composite Index of Child Exposure to Household Material Deprivation}

The composite index of child exposure to deprivation was obtained by applying the IRM to a subset of items. Considering the previous results, item selection was based on two requirements: (1) the item is informative and (2) the item discriminates between households with and without children. The subset of selected items is as follows: HH030_aux and HS160 (housing conditions); HH050, HS011, HS021, HS031, and HS050 (household financial capacity); HS090 and HS110 (comfort goods); and HS170, HS180, and HS190 (housing environment). We recoded ordinal items to dichotomous whenever the respective ICCs overlapped. Appendix A contains the 12 item parameter estimates. The results suggest that the items related to household financial capacity and comfort goods capture the highest 


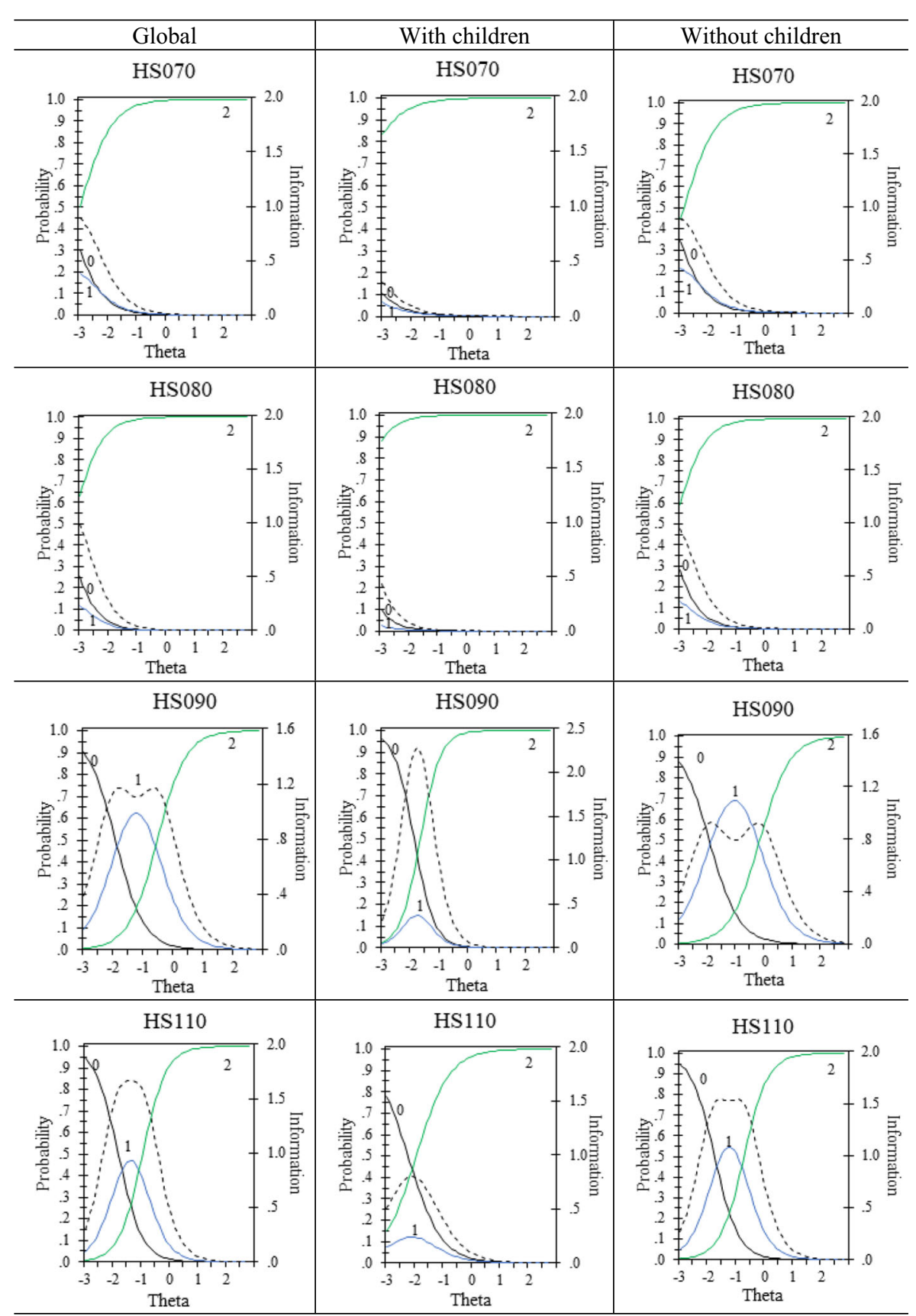

Source: Own calculation (2019).

Fig. 3 Item characteristic curves (ICC) and item information curves (IIC): household durable goods domain items, Source: Own calculation (2019)

levels of deprivation, whereas items related to the environment and housing conditions are related to a lower level of deprivation. 


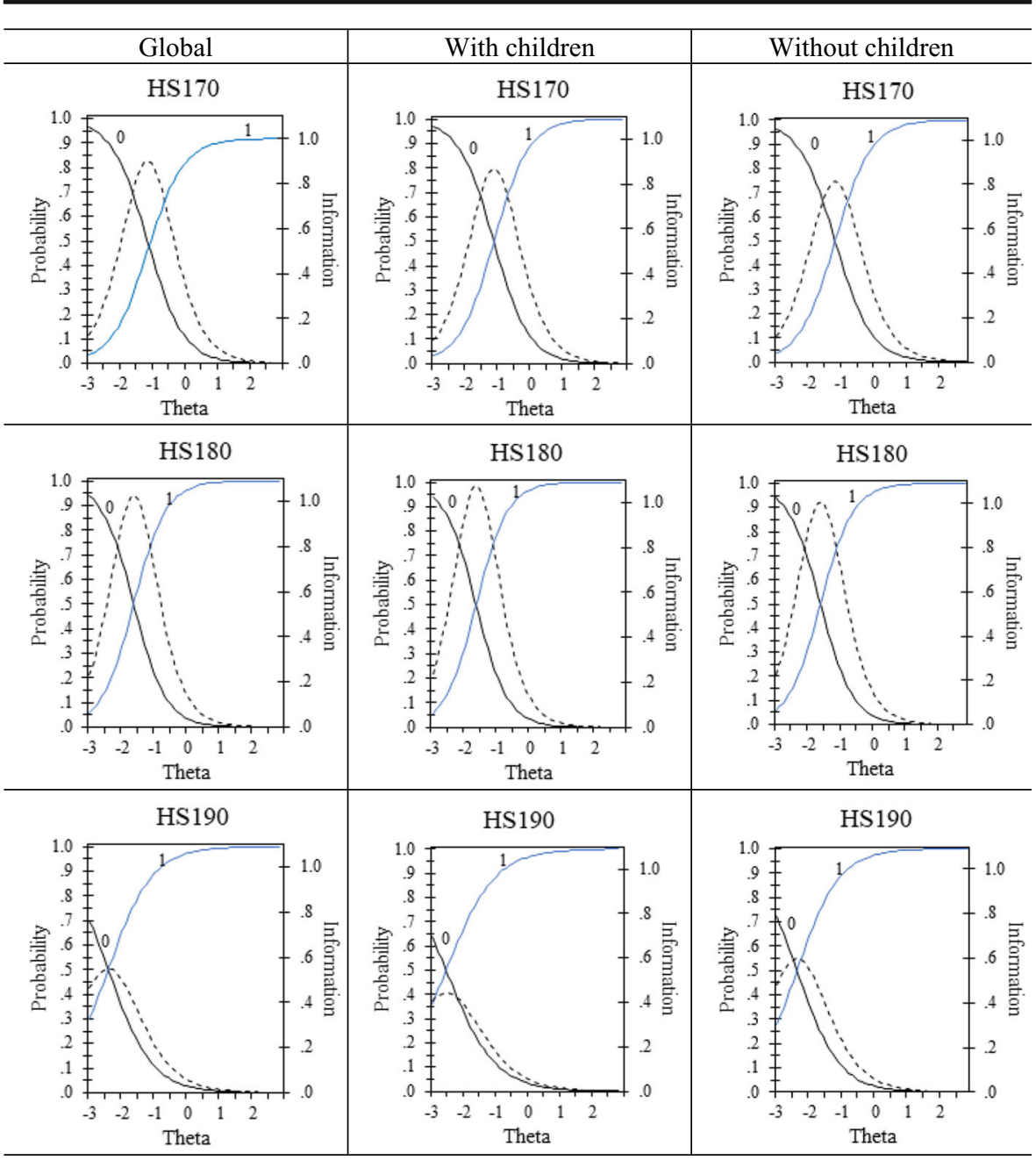

Source: Own calculation (2019).

Fig. 4 Item characteristic curves (ICC) for environment living condition domain items, Source: Own calculation (2019)

Figure 5 illustrates the total information function (TIF, the solid line) and the respective standard of error measurement (the dotted line), which summarize the global information contained in the composite index of child exposure to household material deprivation. As indicated, the composite index discriminates child exposure to deprivation well, and the composite index scores are almost zero for wealthy families.

Considering households with children, Table 3 summarizes the descriptive statistics of the composite index by number of children in the household. The scale unit is a theta SD. Higher values of the composite index indicate lower levels of deprivation. Note that scores decrease as the number of dependent children increases. As the composite index scale is quite asymmetric, we also present the medians. The number of dependent children increases as the severity of child exposure to deprivation increases, and the relative dispersion, quantified by the coefficient of variation $(\mathrm{CV})$, consistently 


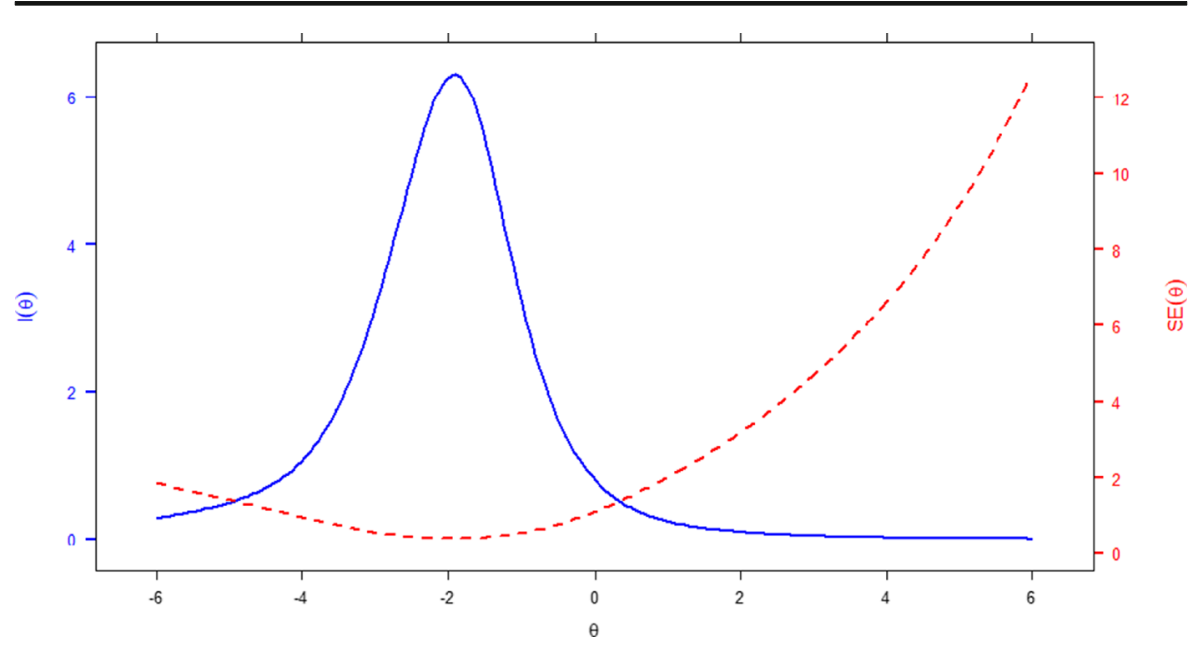

Source: Own calculation (2019).

Fig. 5 Total information function (TIF) for the composite index items, Source: Own calculation (2019)

decreases. That is, whereas exposure to deprivation varies $(\mathrm{CV}=7.46$, one dependent child) in households with few dependent children, in households with a high number of dependent children, exposure to deprivation is almost certain $(\mathrm{CV}=0.84$, four or more dependent children).

\section{Discussion and Conclusion}

This study constructs a measurement of child poverty that involves a multidimensional approach. As the dataset (the EU-SILC) used does not include child-specific information on an annual basis, we propose to measure child exposure to household material deprivation, considering the household as the unit of observation and measurement. We include four domains of deprivation - housing conditions, household financial capacity, household durable goods, and environment living conditions - that have a direct impact on children's wellbeing and development (Saunders and Brown 2019). Following what several researchers have presented regarding the advantages of using a multidimensional approach (Guio et al. 2018; Qi and Wu 2019), our proposal of four domains is based either on a

Table 3 Composite index of child exposure to deprivation by number of dependent children in household

\begin{tabular}{llllll}
\hline Number of dependent children & Mean & Std. Deviation & Median & Minimum & Maximum \\
\hline One child & -0.087 & 0.649 & 0.086 & -2.677 & 0.473 \\
Two children & -0.092 & 0.649 & 0.062 & -2.633 & 0.473 \\
Three children & -0.449 & 0.821 & -0.310 & -2.768 & 0.473 \\
Four children or more & -0.940 & 0.794 & -0.960 & -2.188 & 0.473 \\
Total & $\mathbf{- 0 . 1 2 0}$ & $\mathbf{0 . 6 7 3}$ & $\mathbf{0 . 0 6 2}$ & $\mathbf{- 2 . 7 6 8}$ & $\mathbf{0 . 4 7 3}$ \\
\hline
\end{tabular}

Source: Own calculation (2019) 
theoretical foundation or empirical analysis. Thus, we use separate indexes per domain of children's exposure to deprivation, as well as a composite index.

Domains such as education, health, and social participation would also be important to consider, as well as children's subjective perception of poverty and deprivation (Ben-Arieh et al. 2014). However, this kind of data is not available in the EU-SILC. Our proposal is not a child-centered measurement but a proxy designed to give information about children's living conditions that constitute a set of important determinants of their wellbeing. To our knowledge, child poverty measurements constructed upon the EU-SILC are not available on an annual basis, which strongly limits the necessary monitoring process of children's wellbeing. Moreover, given that the EU-SILC is widely accepted as the most important dataset used to analyze poverty and social exclusion in the EU, our proposal aims to reinforce its potential as a means of evaluating child poverty and deprivation.

The item selection compares the composition of each deprivation domain by applying graded response models (GRM) to three datasets using the 2017 EU-SILC Portuguese sample. The first dataset includes all households in the sample, the second dataset consists of households with children (approximately 30\%), and the third dataset includes households without children. The comparison is based on the item characteristic curves and item information functions for each domain, allowing us to identify the items that discriminate households with children from those without children. Therefore, these items capture children's specificities in terms of household living conditions, which permits evaluation of how these conditions impact their wellbeing. Given the recent child-centric trend in child poverty research (Guio et al. 2018; Qi and Wu 2019), our methodological approach to the EU-SILC data mitigates the lack of poverty-related attributes measured at the child level. Thus, our results are in line with those showing that intra-household inequality matters (Brown et al. 2017), particularly if there are children, and such results reinforce the argument that poverty or deprivation may influence children and adults differently. Although we cannot quantify intra-household variability due to the EU-SILC data design, we did note that households with and without children have different poverty patterns. In fact, the GRM parameter estimates for each set of items considered in the four deprivation domains globally demonstrate the existence of different patterns among the three datasets used. This result highlights the importance of considering these separate datasets and not the whole sample, as other studies do.

The unidimensionality assumption of each deprivation domain is supported by the correlation coefficients of the polychoric matrices and the corresponding first eigenvalues. The diagnosis of the four domains constitutes a contribution to conducting better assessments of child exposure to deprivation, providing important insights for policy design measures and for monitoring and evaluating programs for poverty eradication. In considering a different context, it fully applies that:

The accumulation of this kind of evidence not only produces improved understanding on the nature, level and variation in child wellbeing, it also places increased onus on policy makers, service providers and educators to draw on this kind of evidence when assessing the impacts and effectiveness of their policy interventions. (Saunders and Brown 2019)

The analysis of the items included in each deprivation domain leads to interesting policy design implications. In terms of housing conditions, the item related to the number of 
individuals in the household vs. the household dimensions discriminates the severity level of household conditions in the context of the presence of children, suggesting that households with children are particularly affected by the effects of living in overcrowded houses. This is also the case for the item related to existing problems with a dwelling. Within housing conditions, the lack of a bath or shower in the dwelling captures the lowest levels of deprivation, as the existence of these conditions is almost generalized. Therefore, the results suggest a focus on household living conditions in the context of child poverty, which is consistent with the results of other investigations (Clair 2019; Marsh et al. 2000).

Concerning household financial capacity, the GRM parameter estimates suggest that financial household conditions are well captured by the items related to the existence of arrears. Moreover, participation in the labor market does not protect households from poverty; in fact, the prevalence of in-work poverty is well documented. The generalized low level of salaries limits the capacity to face current living expenses. These items also suggest that households with children face the hardest financial conditions. Further, in the domain of household financial capacity, the item related to the consumption of protein food provides proof only that it is more important at the lower end of its domain scale, suggesting that food scarcity only applies to poorer situations.

Within the domain of comfort goods, the items related to communication facilities and color TV are only important for evaluating situations at the extreme scale values, as these are generalized in the households. However, in the case of the item related to the existence of a computer, discriminatory power is very strong along the scale, suggesting that households with children are particularly affected by the lack of this good. This situation simulates the vulnerability of children regarding cognitive development, educational success, and social participation, in line with the results found in the literature (Pinilla-Roncancio et al. 2019). Attention should be paid in terms of the existence of this kind of good, for example, in schools.

Finally, in what concerns the housing environment domain, it seems that conditions outside the home do not discriminate between households with and without children. However, the GRM estimates suggest the items included within this domain are important tools for evaluating environmental household conditions and, therefore, deprivation.

Our findings also demonstrate that the set of items for deprivation assessment in households with children should differ from the one used with households without children, suggesting that the validity and reliability measurements of child exposure to deprivation require item specificity. To the best of our knowledge, this is the first time such evidence is reported and taken into account.

The composite index of child exposure to household material deprivation includes 12 items, selected from each of the deprivation domains previously described. These items are particularly suitable for discriminating households with children on the left-hand side of the index distribution, in other words, for households with higher levels of deprivation. The score analysis by number of children in the household suggests that large families tend to present higher levels of deprivation, in line with the results from other studies discussed in section 2, and that in such situations, child exposure to deprivation is almost certain.

In terms of future developments, we suggest the following topics: estimation of a deprivation threshold and use of the whole EU-SILC dataset, including other countries and other periods. We did not estimate a deprivation threshold in this study, as we aimed to select the item composition of the indicators constructed, based on rigorous statistical procedures. As the EU-SILC is a common European procedure, the extension 
of this research to other EU members is simple and could offer important information for other regions using the measurements proposed. This is also the case with other periods, which could be important for consolidating the choices made. Also, the use of the longitudinal EU-SILC dataset could be developed in further research. This kind of data would improve the information gathered about impoverishment processes by taking a holistic perspective of children's living conditions.

The measurement proposed to evaluate child exposure to household material deprivation enables monitoring child poverty using a multidimensional measurement based on observations of children's living conditions. This evaluation can be performed on an annual basis and uses the main dataset produced by EUROSTAT to analyze poverty and social exclusion. The information gathered through the proposed measurement could act as a means of operationalizing criteria to evaluate programs, measures, or policies to alleviate poverty. This measurement would also enable the diagnosis of extreme deprivation groups and household profiles, providing strategic information for the design and planning of targeted programs.

Acknowledgements Research supported in part by the Foundation for Science and Technology, FCT/ MCTES through national funds (CEMAPRE-UID/MULTI/00491/2020).

\section{Compliance with Ethical Standards}

Conflict of Interest The authors declare that they have no conflict of interest.

Open Access This article is licensed under a Creative Commons Attribution 4.0 International License, which permits use, sharing, adaptation, distribution and reproduction in any medium or format, as long as you give appropriate credit to the original author(s) and the source, provide a link to the Creative Commons licence, and indicate if changes were made. The images or other third party material in this article are included in the article's Creative Commons licence, unless indicated otherwise in a credit line to the material. If material is not included in the article's Creative Commons licence and your intended use is not permitted by statutory regulation or exceeds the permitted use, you will need to obtain permission directly from the copyright holder. To view a copy of this licence, visit http://creativecommons.org/licenses/by/4.0/.

\section{References}

Ajzenstadt, M., \& Gal, J. (2010). Children, gender and families in Mediterranean welfare states. The Netherlands: Springer. https://doi.org/10.1007/978-90-481-8842-0.

Alkire, S., \& Roche, J. M. (2011). Beyond headcount: Measures that reflect the breadth and components of child poverty. Oxford Poverty \& Human Development Initiative (OPHI), 45, 103-134. https://doi. org/10.1332/policypress/9781847424822.003.0005.

Bastos, A. (2016). A review of child poverty approaches: The European Union experience. in M. Petmesidou, E. Delamonica, C. Papatheodorou, \& A. Henry-Lee (Eds.), Child Poverty, Youth (Un)Employment, and Social Inclusion. Stuttgart: Ibidem-Verlag.

Ben-Arieh, A. (2000). Beyond welfare: Measuring and monitoring the state of children-New trends and domains. Social Indicators Research, 52(3), 235-257.

Ben-Arieh, A. (2008). The child indicators movement: Past, present, and future. Child Indicators Research, 1, 3-16. https://doi.org/10.1007/s12187-007-9003-1.

Ben-Arieh, A., Casas, F., Frønes, I., \& Korbin, J. E. (2014). Multifaceted concept of child well-being. In A. Ben-Arieh, F. Casas, I. Frønes, \& J. Korbin (Eds.), Handbook of child well-being. Dordrecht: Springer. 
Boyden, J., Hardgrove, A., \& Knowles, C. (2012). Continuity and change in poor children's lives: Evidence from young lives. In S. Nandy \& A. Minujin (Eds.), Global child poverty and wellbeing: Measurement concepts, policy and action. Bristol: The Policy Press.

Bradshaw, J., Hoelscher, P., \& Richardson, D. (2007). An index of child wellbeing in the European Union. Social Indicators Research, 80, 133-177.

Brown, C. S., Ravallion, M., \& van de Walle, D. (2017). Are poor individuals mainly found in poor households? Evidence using nutrition data for Africa. NBER Working, 24047 http://www.nber. org/papers/w24047.

Butler, V. (2005). Research report of phase one of the generation 2020 project. Cardiff: Barnardo's Cymru.

Cai, L., du Toit, S. H. C., \& Thissen, D. (2009). IRTPRO: Flexible, multidimensional, multiple categorical IRT modeling. Computer software. Chicago: Scientific Software International.

Chalmers, R. P. (2012). Mirt: A multidimensional item response theory package for the R environment. Journal of Statistical Software, 48(6). https://doi.org/10.18637/jss.v048.i06.

Clair, A. (2019). Housing: An under-explored influence on children's wellbeing and becoming. Child Indicators Research, 12(2), 609-626. https://doi.org/10.1007/s12187-018-9550-7.

Cooper, K., \& Stewart, K. (2013). Does money affect children's outcomes? A systematic review. Joseph Rowntree Foundation. http://eprints.1se.ac.uk/54435/7/CASEreport80.pdf. Accessed X December 2019.

Daly, M., Kelly, G., Dermott, E., \& Pantazis, C. (2012). Intra-household poverty. PSE UK. Economic and Social Research Council: Bristol.

European Commission. (2008). Child poverty and wellbeing in the EU. Current status and way forward. https://fra.europa.eu/en/child-poverty-and-wellbeing-eu-current-status-and-way-forward-0. Accessed X December 2019.

EUROSTAT. (2018). EU-SILC. https://ec.europa.eu/eurostat/web/microdata/european-union-statistics-onincome-and-living-conditions. Accessed X December 2019.

Gordon, D., Nandy, S., Pantazis, C., Pemberton, S., \& Townsend, P. (2003). Child poverty in the developing world. Bristol: The Policy Press.

Grogan, L. (2004). Social transfers and intrahousehold resource allocation: Evidence from Russia. Canadian Economics Association: Ontario.

Guio, A. C., Gordon, D., Marlier, E., Najera Catalan, H., \& Pomati, M. (2018). Towards an EU measure of child deprivation. Child Indicators Research, 11, 835-860. https://doi.org/10.1007/s12187-017-9491-6.

Hattie, J. (1985). Methodology review: Assessing unidimensionality of tests and items. Applied Psychological Measurement, 9(2), 139-164. https://doi.org/10.1177/014662168500900204.

Kiernan, K., \& Huerta, M. (2008). Economic deprivation, maternal depression, parenting and children's cognitive and emotional development in early childhood. The British Journal of Sociology, 59(4), 783-806.

Main, G., \& Bradshaw, J. (2016). Child poverty in the UK: Measures, prevalence and intra-household sharing. Critical Social Policy, 36(1), 38-61. https://doi.org/10.1177/0261018315602627.

Marsh, A., Gordon, D., Heslop, P., \& Pantazis, C. (2000). Housing deprivation and health: A longitudinal analysis. Housing Studies, 15(3), 411-428. https://doi.org/10.1080/02673030050009258.

Masarik, A., \& Conger, R. (2017). Stress and child development: A review of the family stress model. Current Opinion in Psychology, 13, 85-90.

Middleton, S., Ashworth, K., \& Braithwaite, I. (1997). Small fortunes: Spending on children, childhood poverty and parental sacrifice. Joseph Rowntree Foundation: York.

Minujin, A. (2012). Making the case for measuring child poverty. In I. Ortiz, L. Moreira-Daniels, \& S. Engilbertsdóttir (Eds.), Child poverty and inequality: New perspectives. New York: UNICEF.

Nolan, B., \& Whelan, C. (2010). Using non-monetary deprivation indicators to analyze poverty and social exclusion: Lessons from Europe? Journal of Policy Analysis and Management, 29(2), 305-325.

Pahl, J. (2005). Individualisation in couple finances: Who pays for the children? Social Policy and Society, 4(4), 381-391. https://doi.org/10.1017/S1474746405002575.

Pinilla-Roncancio, M., García-Jaramillo, S., Carrero, A, L., González-Uribe, C., \& Ritterbusch, A. (2019). Child vs. household MPIs in Colombia: Do they identify the same children as multidimensionally poor? Child Indicators Research. https://doi.org/10.1007/s12187-019-09639-1.

Qi, D., \& Wu, Y. (2019). Comparing the extent and levels of child poverty by the income and multidimensional deprivation approach in China. Child Indicators Research, 12(2), 627-645. https://doi.org/10.1007 /s12187-018-9544-5.

Reckase, M. D. (1979). Unifactor latent trait models applied to multifactor tests: Results and implications. Journal of Educational Statistics, 4(3), 207-230. https://doi.org/10.3102/10769986004003207.

Ridge, T. (2011). The everyday costs of poverty in childhood: A review of qualitative research exploring the lives and experiences of low-income children in the UK. Children \& Society, 25, 73-84. https://doi. org/10.1111/j.1099-0860.2010.00345.x. 
Samejima, F. (1997). Graded response model. In R.,. K. Hambleton, v. der Linden, \& J. Wim (Eds.), Handbook of modern item response theory. New York: Springer.

Saunders, P., \& Brown, J. E. (2019). Child poverty, deprivation and wellbeing: Evidence for Australia. Child Indicators Research., 13, 1-18. https://doi.org/10.1007/s12187-019-09643-5.

Sutton, L. (2008). The state of play: Disadvantage, play and children's wellbeing. Social Policy and Society, 7(4), 537-549. https://doi.org/10.1017/s147474640800448x.

Tarki. (2010). Child poverty and child wellbeing in the European Union: Report prepared for the DG Employment, Social Affairs and Equal Opportunities (Unite E.2) of the European Commission. TÁRKI Social Research Institute Inc.: Budapest.

Townsend, P. (1979). Poverty in the United Kingdom: A survey of household resources and standards of living. Harmondsworth: Penguin Books Ltd.. https://doi.org/10.1086/227691.

UNICEF. (2004). The state of the world's children 2005: Childhood under threat. New York: UNICEF.

Vasilyeva, M., Dearing, E., Ivanova, A., Shen, C., \& Kardanova, E. (2018). Testing the family investment model in Russia: Estimating indirect effects of SES and parental beliefs on the literacy skills of firstgraders. Early Childhood Research Quarterly, 42, 11-20.

Zampetakis, L. A., Lerakis, M., Kafetsios, K., \& Moustakis, V. (2015). Using item response theory to investigate the structure of anticipated affect: Do self-reports about future affective reactions conform to typical or maximal models? Frontiers in Psychology, 6(September), 1-8. https://doi.org/10.3389/fpsyg.2015.01438.

Publisher's Note Springer Nature remains neutral with regard to jurisdictional claims in published maps and institutional affiliations.

\section{Affiliations}

\section{Maria Eugénia Ferrão ${ }^{1,2}$ - Amélia Bastos ${ }^{2,3}$ • Maria Teresa G. Alves ${ }^{4}$}

1 Universidade da Beira Interior, Rua Marquês d' Ávila e Bolama, 6200-001 Covilhã, Portugal

2 Centro de Matemática Aplicada à Previsão e Decisão Económica (CEMAPRE), Rua do Quelhas, 6, 1200-781 Lisbon, Portugal

3 Instituto Superior de Economia e Gestão (ISEG) - Universidade de Lisboa, Lisbon, Portugal

4 Department of Science Applied to Education, Federal University of Minas Gerais (Brazil), Belo Horizonte, Brazil 